\title{
Academic Colleges in the Galilee: Platforms for Inter- Group Relations
}

\author{
Yaffa Moskovich $^{\mathrm{a}}$, Ido Liberman ${ }^{\mathrm{b}}$
}

\begin{abstract}
This study examines the changes that took place in intergroup relations between Jewish and Arab students in three Israeli colleges in the northern Galilee, as reflected in common traits and behaviors resulting from their shared undergraduate studies. The study investigated whether and how the joint study experience influenced learning and affected intergroup relations for 461 students at different stages of their undergraduate studies. The students answered a four-part questionnaire on cooperative behavior, personality, and demographic traits, and one open question on personal feelings in the college. Results showed that year of studies was a significant factor in creating social ties with other groups, particularly during the third year when students from all groups were more willing to collaborate on study-based activities. A significant effect of object of evaluation (the group evaluated) was found, but not for most other variables and respondents. We conclude that the changes in social relationships are mainly functional. However, change in the attribution of personality traits may be a long-term process and may not be achievable under one academic roof. Possibly this difficulty stems from the Jewish-Arab conflict that hovers in the background and hinders any significant change in perception of character traits.
\end{abstract}

Keywords: intergroup relations, conflict regulation, college students, trait attribution, prejudice

Academic Colleges in the Galilee: Platforms for Intergroup Relations

This study examined the changes in social relations that occur in student populations of colleges in peripheral areas of the northern Galilee. The demographic structure in these colleges is ethnically, religiously, and culturally heterogeneous. Both Jewish and Arab student groups can be further divided into sub-groups. Among the Jews, the divisions may be between religious and secular affiliations, or between the veteran population and new immigrants, such as those from the former Soviet Union or Ethiopia. Differences between Arab college students are essentially religiously based, according to whether they are Muslim, Christian, or Druze. In this research we referred only to two groups: Jews and Arabs (who include the other groups). The study focused on the question of how the academic college forum affects intergroup relations in terms of the existence and power of shared behaviors and attribution of personality traits.

\section{Background}

\section{Intergroup Relations}

Most researchers in the field initially studied the behavior of small groups within a given study (Lawler, 1985; Sherriff, 1966). However, the concept of intergroup relations has been expanded to include the relationship between interethnic relations and relations between races and nations (LeVine \& Campbell, 1972). Intergroup relations are characterized by the development of various negative feelings between the two groups and serve as a platform for the development of stereotypes, prejudice, active discrimination, hatred, and delegitimization (Allport, 1954). A classic study was based on social identity theory (Tajfel \& Turner, 1994), which holds that a person makes continuous comparisons between his or her internal group and the external group in

\footnotetext{
a. Zefat Academic College; Israel

b. Western Academic Galillee College; Israel
}

order to reinforce group identity, but at the price of negative attitudes towards the external group.

\section{Contact Intergroup Relationship}

The study of intergroup relations ranges from inception to the factors which regulate intergroup conflict. The central concept is the 'social contact hypothesis' which Williams (1947) was the first to formulate. Under this approach, contact between people of different groups will reduce prejudice and tension between them. Allport (1954) created a taxonomy for organizing the structure and effects of social contact. His taxonomy presented the following parameters: quantitative (frequency, duration, number of people involved, range); status of those involved; the basis of the contact (competitive, cooperative, voluntary or imposed); and the atmosphere surrounding the contact and type of contact (temporary, residential, work-related, civil, or religious).

Intergroup contact can reduce prejudice in a variety of intergroup situations. This was discovered by Pettigrew and Troop (2006), by examining 696 samples. The result supports a variety of different ethnic groups, age groups, and geographical areas (Pettigrew \& Troop, 2006: 766). Binder et al. (2009) observed in a multicultural contact in a secondary school that prejudice was reduced under close and intimate relations.

These findings can be explained by building trust, positive mood, and acceptance as key factors, 0 that facilitate intergroup relationships and overcome prejudice (Troop, 2006).

Most studies in intergroup relationships were conducted among students in higher education institutions by intentional controlled research and meetings (Golan \& ShalhoubKevorkian, 2014; Pettigrew \& Troop, 2006, 2008, 2011; Troop, 2006; van Laar et al, 2008). Intergroup contact contributes to the improvement of relations and atmosphere in universities (Binder et al., 2009; Dovidio, Gaertner, \& Kafati, 
2003; Golan \& Shalhoub-Kevorkian, 2014; Pettigrew \& Tropp, 2006, 2008, 2011; Sidanius, Levin, van Laar, \& Sears, 2010; van Laar et al., 2005).

Criteria for intergroup relationships to reduce prejudice: meetings.

1. Direct cross-group interaction: face to face

2. The participant has information about the outgroup.

3. Interaction between defined and different groups.

4. Intergroup relationship causes changing attitude toward out-groups in general, not only with the one person by individual contact (Binder et al., 2008; Sidanius et al., 2008; van Laar, Levin, Sinclair, \& Sidanius, 2005).

5. The assessment was based on individuals' data (Pettigrew \& Troop, 2011).

6. Intergroup contact relations occurred under several conditions: equity of status, common goals, cooperative task, friendly non-threatening situation, reducing anxiety about intergroup contacts and increasing empathy to the out-group, enhancing knowledge about the out-group, institutional support (see Allport, 1954; Amir, 1976; Cook, 1978; Hewstone \& Brown, 1986; Pettigrew, 1971; Pettigrew \& Troop, 2000, 2006, 2011).

To test the effect of intergroup relation, the level of generalization beyond the original contact situation must be estimated. This kind of generalization can be defined as secondary transfer effect (Pettigrew, 2009). It can be expressed by the willingness of an individual to create contacts with other members of the out-group not involved in the past with direct contact by deprovincialization, intergroup relationships that broaden experience and complex contact opportunities. Secondary transfer effect occurs when the outgroup is more closely related and contact occurs more frequently (Pettigrew \& Troop, 2011).

In contrast, some researchers have found that the encounter actually strengthens stereotypes and negative labeling. This leads to separation between groups and a heightened sense of social injustice in the minority one, as seen in meetings initiated between white, Latino, and black students in the U.S. (Dovidio et al., 2000; Hornsey \& Hogg, 2000; Schmader, Major, \& Gramzow, 2001; Troop, 2006). In these cases it is better to restore 'avoidance of contact' for resolving conflicts. This involves excluding members of rival groups until the conflict disappears (Boulding, 1957, 1963). Conflict based on race, ethnicity, or culture may lead to social segregation and minimal contact, which in itself reduces conflicts (Baumgartener, 1988; Tajfel \& Turner, 1994).

The 'model of social adjustment' (Eshel, Kurman, Zehavi, \& Sbeit, 2007) presents solutions for regulating intergroup conflicts. The model lists four strategies that the minority group may adopt for dealing with the values of the majority: assimilation, integration, segregation, and sidelining. Other researchers have suggested that the attitude of the majority towards the minority group is a major factor in the social adjustment of the minority group (Eshel et al., 2007; Schwarzwald \& Tur-Kaspa, 1997). Humiliation and rejection by mainstream society create negative attitudes in minority groups and a reluctance to adopt the dominant culture (Kimmerling, 1998). Choosing assimilation or social integration will create the motivation to engage in social relations with the majority group, but choosing segregation will lead to a negative attitude towards the majority.

Another solution for resolving conflicts among heterogeneous ethnic groups was tested successfully by jigsaw classroom technique (Aronson, Blaney, Stephin, Sikes, \& Snapp, 1978). This technique was used in small group learning, by pursuit of common goals. This strategy demands that every student cooperate and participate with his friends by becoming an expert. The jigsaw method can facilitate overcoming prejudice; it was tested on multicultural and pluralism ethnical diversity. "A jigsaw student is challenged to develop empathy and tolerance" (Aronson et al., 1978: 37), since the group is heterogeneous by different racial or ethnic groups and the learning task demands that the student be flexible and open to new ideas.

\section{Relations between Jewish and Arab Students in Higher Education}

In Israel, the college admission threshold is lower than that of the universities (Davidovitch \& Iram, 2005). Hence, there are more students from disadvantaged groups, such as Israeli Arabs and students of Ethiopian origin, in colleges in the north and south of the country (known as the periphery) (Soen, 1999). While Israeli Arabs represent $8.5 \%$ of university enrolments, they comprise over $30 \%$ of the enrolment at peripheral colleges. Moreover, scholarly achievement differs from Jewish to Arab students. Average scores of Arab students are lower in schools and academia than those of the Jewish majority (Council for Higher Education, 2013; Lufi \& Parish-Plass, 2010). Despite these differences, Arab students attribute importance to higher education (Rabinowitz \& Khawla, 2002; Rinawi, 2003). For this reason, Arab students have stronger motivation to interact with Jewish students than their Jewish counterparts, rather than withdraw into their own group (Davidovitch, Soen, \& Kolan, 2009; Yuchtman-Ya'ar \& Shavit, 2001). This asymmetry characterizes majority-minority relations throughout the world: where the minority group wants to participate in the success of the majority. Thus, the self-esteem of Arab students in Israel rises in proportion to their success and integration into Israeli society (Arad, 2007).

Meetings in an academic setting in Israel show differing trends. Al Haj (1994) reported that a joint study meeting at the University of Haifa did not lead to interaction between Jewish and Arab students. In contrast, Arab students at the College of Judea and Samaria, the Western Galilee College, and the Open University of Israel were receptive to meeting, and reported interaction with Jewish students when involved in learning tasks (Davidovich et al., 2006, 2009; Rinawi, 2003). Meetings by controlled research between Arab and Jewish students at the Ben-Gurion University of the Negev also contributed to the reduction of prejudice and defense mechanisms in the two groups (Agmon, Schneider, \& Sagy, 2005), and in eleven Israeli academic institutions (Golan \& Shalhoub-Kevorkian, 2014).

\section{Rationale}

The current research explores how learning encounters in college affect intergroup relations in terms of the existence and power of shared behaviors and attribution of personality traits. One can assume that the learning encounter leads to a sense of commonality based on the desire to integrate into a given society (Eshel et al., 2007; Pettigrew, 2009; Pettigrew 
\& Tropp, 2011). Many researchers from the school of the 'contact hypothesis' have suggested that it creates a positive change of group attitude (general, not only with the one person by individual contact) (see Allport, 1954; Amir, 1976; Binder et al., 2008; Cook, 1978; Hewstone \& Brown, 1986; Pettigrew \& Tropp, 2000, 2006, 2011; Sidanius et al., 2008; van Laar et al., 2005). However, other studies have suggested that the learning encounter will reflect polarization and negative attitudes of minority groups towards the majority (Baumgartner, 1988; Boulding, 1957, 1963) or the desire of the minority group to keep its distance (Eshel et al., 2007). We assume that the types of interactions and their intensity will be connected to secondary transfer effect (Pettigrew, 2009; Pettigrew \& Tropp, 2011), since they do not take place in the classroom. This can be expressed by the willingness for intergroup interactions.

\section{Research Model, Hypotheses, and Method}

A research model was created to represent the predicted relationship between the explanatory and mediator variables and the dependent variables, which express the intergroup attitudes. We examined the effect of changing the amount of exposure by social group, and the two variables were expressed in terms of intergroup perception: perception of personality characteristics and types of interactions and their intensity.

\section{Research Model}

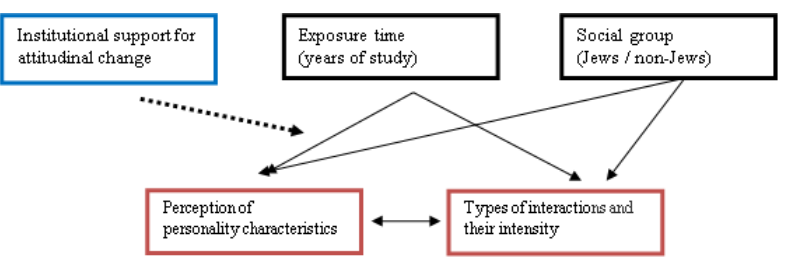

The following hypotheses were formulated:

1. The more veteran the students, the more positive their attitudes toward other groups would be.

2. The more veteran the students, the greater the interaction with students from other groups would be.

The participants were undergraduate students at the academic colleges of Safed (the capital of the Northern Galilee), Kinneret (on the southern shore of the Sea of Galilee), and Western Galilee (in Acre). There were 461 undergraduates who participated, ranging from first-year students at the beginning of the school year to students at the end of second year and beyond. Table 1 shows their characteristics.

Table 1. Frequencies of the Students's Sample

\begin{tabular}{|c|c|c|c|c|c|c|c|}
\hline & & \multicolumn{2}{|c|}{ Jewish Students } & \multicolumn{2}{|c|}{ Arab Students } & \multicolumn{2}{|c|}{ All students } \\
\hline & & Num. & $\%$ & Num. & $\%$ & Num. & $\%$ \\
\hline \multirow{3}{*}{ Academic year } & Beginning of $1^{18}$ year & 56 & 32.496 & 117 & $67.6 \%$ & 173 & 100.096 \\
\hline & End of $1^{12}$ year & 105 & $62.1 \%$ & 64 & $37.9 \%$ & 169 & $100.0 \%$ \\
\hline & Second year \& beyond & 76 & $63.9 \%$ & 43 & $36.1 \%$ & 119 & 100.096 \\
\hline \multirow{2}{*}{ Gender } & Male & 60 & $55.0 \%$ & 49 & $45.0 \%$ & 109 & $100.0 \%$ \\
\hline & Female & 179 & $50.6 \%$ & 175 & $49.5 \%$ & 354 & $100.0 \%$ \\
\hline \multirow{4}{*}{ Age Groups } & $18-22$ & 39 & $19.0 \%$ & 166 & $81.0 \%$ & 205 & 100.096 \\
\hline & $23-25$ & 93 & $78.5 \%$ & 25 & $21.2 \%$ & 118 & $100.0 \%$ \\
\hline & $25-30$ & 47 & $82.5 \%$ & 10 & $17.6 \%$ & 57 & $100.0 \%$ \\
\hline & $31+$ & 61 & $71.5 \%$ & 24 & $28.3 \%$ & 85 & 100.096 \\
\hline & TOTAL & 237 & $51.4 \%$ & 224 & $48.6 \%$ & 461 & $100.0 \%$ \\
\hline
\end{tabular}

Two groups of students (Arabs and Jews) answered a questionnaire which checked four areas: shared behavior, evaluation of personality traits, demographic data, and an open question about the atmosphere of each college, and how the student feels in the academic institution. The importance of this question is aimed especially at minority groups.

Shared behavior questions related to five common behaviors ranging from studying in a shared course to shared social pastimes outside the college, and the respondents were asked to answer on a six point scale regarding the extent to which they engaged in such behaviors with other students in the college. The second part of the questionnaire dealt with the attribution of personality traits and included five relevant features: loyalty, reliability, intelligence, sociability, and humaneness. Respondents gave their assessment of these features from extremely low to extremely high for each of the three groups of students on a five-point scale. In the third part, respondents answered a variety of questions aimed at deriving a demographic profile of the participants. The questionnaire was offered to students in parallel versions in Hebrew and Arabic, and was carefully validated before use.

\section{Results}

The purpose of this research was to examine the influence of having joint-study groups, comprising students of different national and cultural backgrounds, on the attitudes and perceptions of the members of those groups to their ingroup and out-group. It was assumed that the presence of students from different ethnic backgrounds in the same courses would encourage and promote positive attitudes of the members of one ethnic group to members of the out- (other ethnic) group. Thus, we hypothesized that as students increasingly experienced the joint-study group, there would be a more positive evaluation of the personality characteristics of the members of the out-group. We also hypothesized that as students of different ethnic groups continued working together, the intensity of those students' common activities would increase. Below is a one-way Analysis of Variance test examining the hypotheses, comparing the difference in the intensity of interaction, over time, for the reference group towards the "out-group" and towards itself.

Table 2. Differences between Students by Academic year on Intensity of Interaction 


\begin{tabular}{|c|c|c|c|c|c|c|c|c|}
\hline & \multicolumn{2}{|c|}{$\begin{array}{c}\text { Beginning of } 1^{2} \\
\text { year } \\
(n=112)\end{array}$} & \multicolumn{2}{|c|}{$\begin{array}{l}\text { End of } 1^{x} \text { year } \\
\qquad(n=183)\end{array}$} & \multicolumn{2}{|c|}{$\begin{array}{c}\text { Second year \& } \\
\text { beyond } \\
(n=130)\end{array}$} & \multirow[b]{2}{*}{$f$} \\
\hline & & M & S.D & $\mathrm{M}$ & 5.0 & $\mathrm{M}$ & 5.0 & \\
\hline \multirow{5}{*}{ 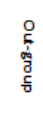 } & Joint studes & 3.29 & 1.40 & 4.17 & 1.40 & 4.35 & 1.36 & $20.45 \cdots$ \\
\hline & Basic cooper ation in stud ies & 2.37 & 1.42 & 2.69 & 1.58 & 3.33 & 1.67 & $12.01 \cdots$ \\
\hline & 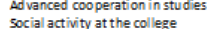 & 2.11 & 1.300 & 2.144 & 1.51 & 2.55 & 1.78 $>>0$ & \\
\hline & & & $\begin{array}{l}1.39 \\
1,20\end{array}$ & $\begin{array}{l}2.36 \\
1.73\end{array}$ & 清1 & & & \\
\hline & in tensity of interaction & 2.37 & 1.08 & 2.61 & 1.16 & 3.01 & 1.31 & $9.09 \cdots$ \\
\hline & Joint studes & 4.68 & 1.13 & 4.03 & .90 & 4.13 & 1.00 & $16.66 \cdots$ \\
\hline & $\begin{array}{l}\text { Basic cooperation in stud ies } \\
\text { Sarcos }\end{array}$ & 4,30 & 1.32 & 3.74 & 1.03 & 4.01 & 1.10 & ${ }_{5.58}^{8 . *}$ \\
\hline & 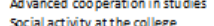 & (3.979 & 1.59 & 3.378 & 1.12 & $\begin{array}{l}3.57 \\
402\end{array}$ & & \\
\hline & 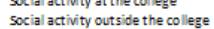 & ${ }_{336}^{3}>0$ & $\begin{array}{l}1.150 \\
1.82\end{array}$ & $\begin{array}{l}3.18 \\
3.01\end{array}$ & 1.29 & 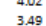 & 139 & $3.51 *$ \\
\hline & Int thensity of interaction & 4.11 & 1.15 & 3.59 & .81 & 3.84 & .95 & $10.26 \cdots$ \\
\hline
\end{tabular}

The findings presented in Table 2 support Hypothesis 1 , that there is a positive correlation between time spent together and the intensity of interactions. This finding is significant for all variables, except the variable of "social activities in college."

Advanced analysis, of the Sheffe type, found that significant differences are usually between the students in the second year (or beyond) and students in the first year (both at the beginning and at the end). In addition, in regard to the variable of "joint studies" the difference is reversed: between new students in the first year and students ending the first year and in the second year (and beyond). Beyond that, regarding the interactions with the "out-group," Table 1 indicates a correlation between increasingly massive interaction and a relative decline in the level of interaction among all three groups. This reflects intermediate, or lower, estimations of all interactions in all three groups (with an approximate score of 4.00 or lower, on a 6-point scale).

The table also shows the values of the intensity of the interactions with the in-group of the respondent. This presentation, even though it wasn't part of the hypothesis of the study, may possibly shed light on what the students experience during their studies. In connection with this, we can see that the students experience precisely the reverse. In almost all the types of interaction there is a drop from reasonably high interaction at the beginning of the first year to less significant interaction at the other points of measurement. Here there is also a significant decline, so that regarding most of the variables the students at the beginning of the first year estimated the intensity of the interactions to be of a relatively high and significant level, relative to the other two points of measurement. It is worth noting that in general, the interactions with the in-group were estimated to be at a higher level than with the out-group, and that the most significant decline is between the beginning and end of the first year, whereas the students in the second and subsequent years estimated the interactions to be at a slightly higher level than at the end of the first year.

An identical analysis was also carried out on variables of perceiving personality traits. The results of this analysis are presented in Table 3 below.

The findings of this analysis are unequivocal; there is no significant difference between the years regarding any of the variables. This finding is correct, regarding both the out-group and in-group. In light of this, we can say that there is no basis for the second research hypothesis, which refers to this group of variables. At the same time, the direction of the findings supports those outlined by the research hypothesis. It can be seen that in analysis related to the out-group, there is a significant and consistent increase between the beginning and end of the first year; this assessment drops a little among the students studying in the second and subsequent years, but does not return to the levels of the beginning of the first year, meaning we can say that there is an improvement over the years, even if this improvement is not significant. We can also see a similar phenomenon in connection with the in-group meaning a rise in the perception of personality traits between the beginning and end of the first year, followed by a certain drop among the students in their second and subsequent years.

Table 3. Differences between Students by Academic year on Personality Traits

\begin{tabular}{|c|c|c|c|c|c|c|c|c|}
\hline & \multicolumn{2}{|c|}{ Beginning of $1^{x}$ year } & \multicolumn{2}{|c|}{ End of $1^{22}$ year } & \multicolumn{2}{|c|}{ Second year \& } & \multirow[b]{3}{*}{$\mathrm{F}$} \\
\hline & & \multicolumn{2}{|c|}{$(n=112)$} & \multicolumn{2}{|c|}{$(n=183)$} & \multicolumn{2}{|c|}{$(n=130)$} & \\
\hline & & M & S.D & M & S.D & M & 5.0 & \\
\hline \multirow{6}{*}{ 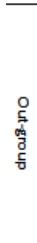 } & Loyalty & 2.92 & 1.09 & 3.07 & 1.24 & 3.10 & 1.15 & .80 \\
\hline & Reliability & 3.07 & 1.19 & 3.11 & 1.20 & 3.18 & 1.17 & .24 \\
\hline & Wisdom & 2.55 & 1.01 & 2.82 & 1.15 & 2.71 & 1.16 & 2.01 \\
\hline & Friendliness & 2.68 & 1.08 & 2.96 & 1.26 & 2.71 & 1.17 & 2.58 \\
\hline & Humanity & 2.48 & 1.07 & 2.75 & 1.30 & 2.59 & 1.17 & 1.82 \\
\hline & $\begin{array}{l}\text { Personality } \\
\text { characteristics }\end{array}$ & 2.73 & .81 & 2.93 & 1.00 & 2.87 & .89 & 1.48 \\
\hline \multirow{6}{*}{ 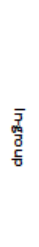 } & Loyalty & 2.51 & .98 & 2.48 & .90 & 2.36 & .87 & .80 \\
\hline & Reliability & 2.39 & .89 & 2.43 & .88 & 2.44 & .91 & .09 \\
\hline & Wisdom & 2.20 & .73 & 2.26 & .84 & 2.16 & .71 & .60 \\
\hline & Friendliness & 2.12 & .88 & 2.33 & .87 & 2.31 & .80 & 2.39 \\
\hline & Humanity & 2.13 & .85 & 2.16 & .94 & 2.11 & .81 & .09 \\
\hline & $\begin{array}{l}\text { Personality } \\
\text { characteristics }\end{array}$ & 2.27 & .64 & 2.33 & .74 & 2.28 & .65 & .24 \\
\hline
\end{tabular}

$* p<.05 . * * p<.01 . * * * p<.001$

The findings of this analysis are unequivocal; there is no significant difference between the years regarding any of the variables. This finding is correct, regarding both the out-group and in-group. In light of this, we can say that there is no basis for the second research hypothesis, which refers to this group of variables. At the same time, the direction of the findings supports those outlined by the research hypothesis. It can be seen that in analysis related to the out-group, there is a significant and consistent increase between the beginning and end of the first year; this assessment drops a little among the students studying in the second and subsequent years, but does not return to the levels of the beginning of the first year, meaning we can say that there is an improvement over the years, even if this improvement is not significant. We can also see a similar phenomenon in connection with the in-group meaning a rise in the perception of personality traits between the beginning and end of the first year, followed by a certain drop among the students in their second and subsequent years

We can conclude up to this point, that the first hypothesis, which discusses the differences existing between students in the intensity of reported interactions with the outgroup, based on the length of time they have studied, is supported by the study findings. In contrast, for the second hypothesis, no support was found for the differences existing between students concerning their perception of personality 
traits among the out-group, based on the length of time they have studied, although the direction of the difference matches the research hypothesis. It was also found regarding the ingroup, that there is a significant drop over the years in the intensity of the interactions, whereas there was no significant rise or fall in the perception of personality traits.

We will now examine the next pair of hypotheses, which examine the differences between Jewish students who are the majority group and the non-Jewish students who comprise the minority group, as described in Hypotheses 3 and 4. These differences were examined using the independent samples ttest, and they are presented in Tables 4 and 5.

Table 4. Differences between Students by Type of Group on Intensity of Interaction

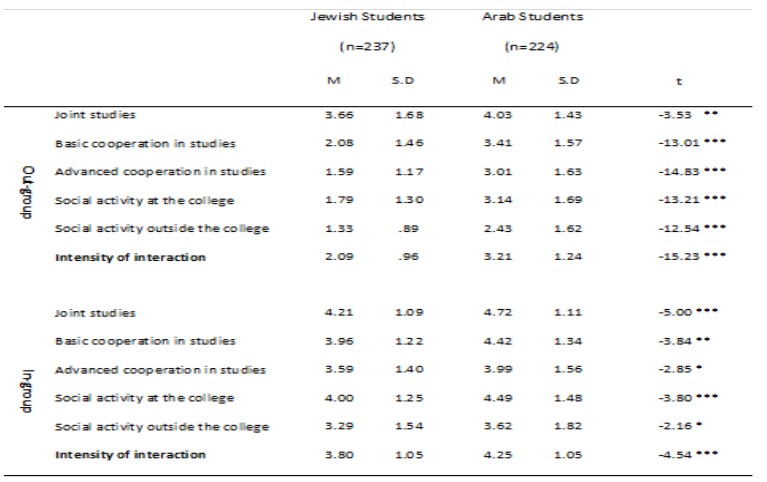

$* p<.05 . * * p<.01 . * * * p<.001$

Table 5. Differences between Students by Type of Group on Personality Traits

\begin{tabular}{|c|c|c|c|c|c|}
\hline & \multirow{2}{*}{\multicolumn{2}{|c|}{$\begin{array}{l}\text { Jewish Students } \\
(\mathrm{n}=237)\end{array}$}} & \multirow{2}{*}{\multicolumn{2}{|c|}{$\begin{array}{l}\text { Arab Students } \\
(n=224)\end{array}$}} & \multirow[b]{3}{*}{ T } \\
\hline & & & & & \\
\hline & $\mathrm{M}$ & S.D & $\mathrm{M}$ & 5.D & \\
\hline Loyalty & 3.30 & 1.31 & 2.84 & 1.09 & $5.50 \cdots$ \\
\hline Reliability & 3.44 & 1.29 & 2.83 & 1.10 & $7.39 \cdots$ \\
\hline §̣ Wisdom & 2.90 & 1.22 & 2.60 & 1.00 & $4.00 *$ \\
\hline 醇 Friendliness & 2.98 & 1.30 & 2.68 & 1.17 & $3.52 \cdots$ \\
\hline Humanity & 2.74 & 1.36 & 2.66 & 1.08 & .97 \\
\hline Personality characteristics & 3.07 & 1.06 & 2.72 & .79 & $5.43 \cdots$ \\
\hline Loyalty & 2.30 & .93 & 2.44 & 1.06 & -1.54 \\
\hline Reliability & 2.30 & .85 & 2.36 & 1.04 & -.69 \\
\hline Wisdom & 2.02 & .73 & 2.36 & .90 & $-4,41 *$ \\
\hline $\begin{array}{l}\vec{c} \text { F Friendliness } \\
\bar{\tau}\end{array}$ & 2.14 & .82 & 2.15 & .98 & -.11 \\
\hline Humanity & 1.91 & .85 & 2.17 & .96 & $-2.99^{*}$ \\
\hline Personality characteristics & 2.13 & .66 & 2.30 & .74 & $-2.58^{*}$ \\
\hline
\end{tabular}

$* p<.05 . * * p<.01 . * * * p<.001$

The findings in Tables 4 and 5 unequivocally support the hypotheses which discuss the difference between the two groups of students - Jews and non-Jews. Table 4 shows that there is a difference between all the examined variables, and that this difference is highly significant. This finding is correct for the in-group, and even more so for the out-group. Regarding all the variables, the group of non-Jewish students reports a greater intensity of interactions with others - regarding both the out-group and in-group - than the Jewish students.

Table 5, which illustrates the difference between Jewish students and non-Jewish students regarding evaluation of personality traits, presents complex findings. Regarding the outgroup, the evaluation of the non-Jewish students is significantly lower than that of the Jewish students regarding their out-group. In contrast, when we focus on evaluating the personality traits of the in-group, the non-Jewish students evaluate the personality traits more highly than the Jewish students evaluate the personality traits of their own in-group. At the same time, the findings of the second part of Table 5 are only partially significant.

To enrich the research findings, we examined these findings together with the evaluating group. That is, we wished to find out if, in addition to the effect of years of study on the dependent variables, there is additional effect of the evaluating group - Jews or non-Jews. To investigate this possibility, we carried out a two-way ANOVA of years of study and the group with dependent variables, both within the out-group and the ingroup. These analyses were only carried out on the variables summarizing each part: the intensity of the interaction and perception of personality traits. Tables 6 and 7 and Figures 1 and 2 below show the results of this analysis on the out-group:

Table 6. Effect of Group Type and the Academic Year on Intensity of Interaction

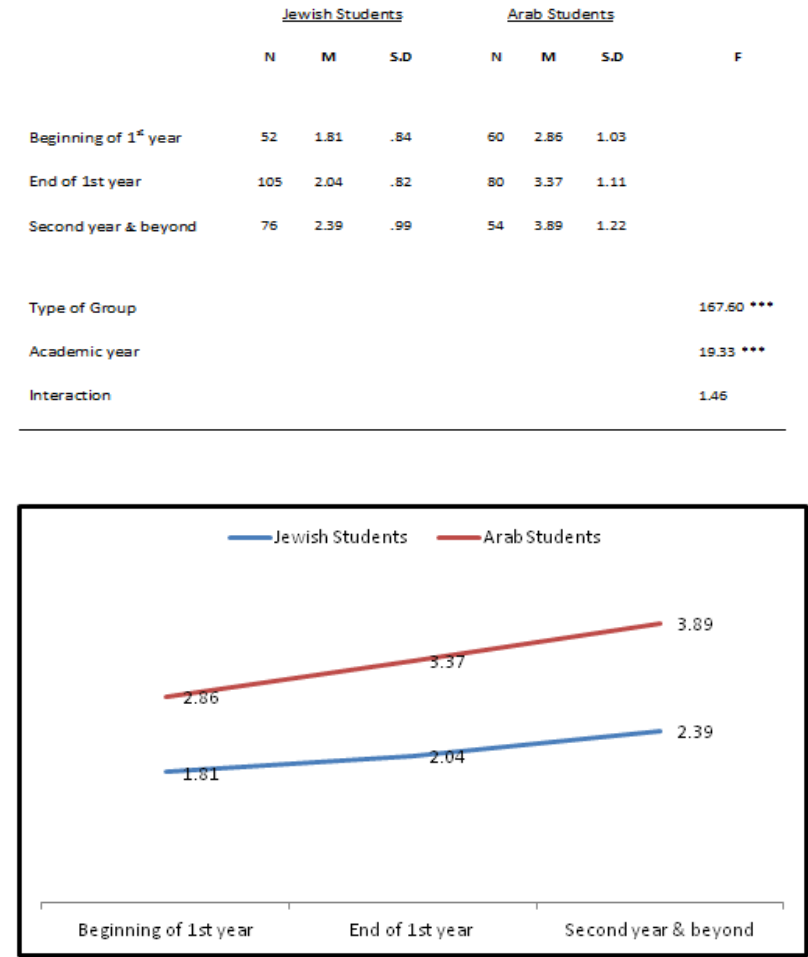

Figure 1. Effect of Group Type and the Academic Year on Intensity of Interaction

Table 7. Effect of Group Type and the Academic Year on Personality Traits 


\begin{tabular}{|c|c|c|c|c|c|c|c|}
\hline & \multicolumn{3}{|c|}{ Jewish Students } & \multicolumn{3}{|c|}{ Arab Students } & \multirow[b]{2}{*}{$\mathrm{F}$} \\
\hline & N & м & S.D & N & м & SD & \\
\hline Beginning of $1^{2 x}$ year & 50 & 3.06 & .89 & 60 & 2.46 & .62 & \\
\hline End of 1st year & 99 & 3.02 & 1.13 & 79 & 2.80 & .81 & \\
\hline Second year \& beyond & 73 & 3.08 & .91 & 52 & 2.57 & .79 & \\
\hline Type of Group & & & & & & & $23.74 \cdots$ \\
\hline Academic year & & & & & & & 1.01 \\
\hline Interaction & & & & & & & 1.50 \\
\hline
\end{tabular}

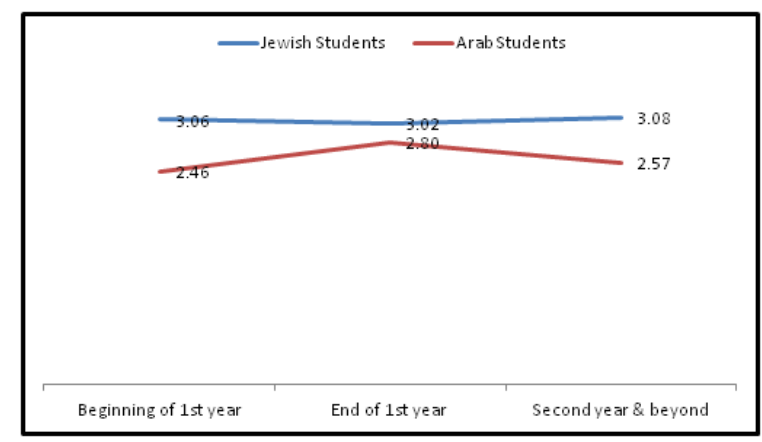

Figure 2. Effect of Group Type and the academic year on Personality characteristics

The findings shown in Table 3 and Figure 1 show that each of the independent variables - year of study and type of group - has a significant effect on the estimation of the intensity of interaction with the out-group. We can see that in both groups - Jews and non-Jews - there is almost linear growth through the three points of measurement, beginning with low evaluation at the beginning of the first year, and ending with a relatively high evaluation from the second year onwards. We can also see that there is a clear difference between evaluation by the Jews and non-Jews. While the evaluation of the intensity of the interaction among the Jews is relatively low, this evaluation is higher among the non-Jews during all three points of measurement. It also emerges from the data in Table 3 and Figure 1, that there is no interaction between these variables and that each of them affects the data of the participants, without connection or dependence on the second variable.

The findings shown in Table 7 and Figure 2 show that, as we have already seen (in Table 2), the school year variable does not affect the evaluation of perspective of personality traits of the out-group; this finding is true for both groups Jews and non-Jews. In contrast, it was found that Jews estimate the personality traits of the out-group to be significantly higher than the non-Jews, for all three points of measurement, from the beginning of the first year up until students from the second and subsequent years. It also emerges from the table that there is no interaction between the two variables under the influence of the dependent variable.

The findings from the open question can teach us that Arab students felt very happy in the academic institutions. Arab students were satisfied with the treatment they received from the official staff. They reported to us that they felt that the college shows them a fair, friendly, and honest attitude. The Arab students wrote to us that they were especially impressed by the lecturers, that the teachers inspired them, and demonstrated a personal example of how to treat others, and behave in a respectful way. They felt that the academic college gave them a real opportunity for success in academic learning.

Arab students from all groups expressed very positive attitudes towards the Jewish lecturers. 'It was surprising to discover how humane and wonderful they were'. As mentioned above, the college lecturers play an important role in changing attitudes. In contrast, the Arab lecturers were perceived negatively: 'They are arrogant and dismissive towards us, and do not treat us nicely.'

The Jewish students also reported a positive learning experience in the academic institutions. As one student said, 'Being at college has affected my attitudes, but I have been especially influenced by the lecturers, which gives a good feeling'. This sentiment was echoed by many others; college faculty played a crucial role in reducing tension between the groups. The lecturers served to convey democratic, egalitarian, and liberal values. The fair and humane attitude of lecturers to all students made Arab students feel more positive about others. As one student said, 'Academic studies gave me the feeling that equality is possible, and this should be separated from the national problem'.

\section{Discussion}

The findings show that all groups would like social contact for study and social gatherings even outside the college, but there was little change in attitude towards the attribution of stereotypes among Jews and Arabs. There appears to be a contradiction between the behavioral (the desire for social contacts) and the cognitive, where the change was small (change in attributing stereotypes). The variable of time had an effect on two variables. The first was the rapid and significant effect of desire for social interaction, when in the senior year greater willingness to establish social contacts was seen than in earlier years, while the second, the variable of personality traits, had a smaller and slower effect, although the process for each group differs slightly. How can these conflicting trends be explained?

In terms of the social contact hypothesis (Williams, 1947), the encounter between Jews and Arabs in the Galilee colleges promoted willingness to establish social contacts. This can be attributed to the conditions of equality to which the students were exposed, where they had to compete only on the basis of academic achievement (Allport, 1954; Amir, 1976; Binder et al., 2008; Cook, 1978, 1984; Hewstone \& Brown, 1986; Pettigrew, 1971; Pettigrew \& Troop, 2000, 2006, 2011; Sidanius et al., 2008; van Laar et al., 2005).

This tendency has also been shown in other studies in Israel (Davidovich et al., 2006; 2009; Golan \& ShalhoubKevorkian, 2014). The contact was voluntary, without the intervention of the institution, compared to one U.S. study where meetings between white, Latino, and black students were artificially initiated (Dovidio et al., 2000; Hornsey \& Hogg, 2000; Schmader et al., 2001; Troop, 2006). Similar studies have been carried out in Israel between Jewish and Arab students (Halevy, 2000; Litvak-Hirsch \& Bar-On, 2008; 
Nahum, 2006). Participants in the present study had equal status - all were undergraduate students. It is important to mention the acknowledged institutional support and good atmosphere (from the open question data), and all Arab students praised the fairness of the lecturers (Amir, 1976; Cook, 1978; Dovidio et al., 2003; Hewstone \& Brown, 1986; Pettigrew, 1971; Pettigrew \& Troop, 2000).

In terms of the social adjustment model (Eshel et al., 2007), both the Israeli Arabs, whether Muslim or Druze, and the Jews, engaged in social integration that created motivation to forge social relations. The Arab students in this study constituted a minority group but did not experience culture shock or feel rejection or discrimination (Shwarzwald \& TurKaspa, 1997). Their willingness and openness to social contact can be explained by the institution's atmosphere to which the Arab students were exposed. Both administrative staff and lecturers at these small Galilee colleges welcome Arab students very positively. The Arab students were surprised by the warm ties established with the Jewish teachers (Eshel et al., 2007). Contrary to the findings of Kimmerling (1998), Arab students at colleges in peripheral areas of the Galilee will not experience politically-based conflicts and hostility (Rabinowitz \& Khawla, 2002: 56), but rather find a sympathetic and supportive framework (Davidovich et al., 2006, 2009).

The findings support previous studies showing that Arab students in Israel are more receptive to social relations with Jews than vice versa (Davidovich et al., 2006, 2009; Golan \& Shalhoub-Kevorkian, 2014; Rinawi, 2003; Yuchtman-Ya'ar \& Shavit, 2001). This explanation is consistent with the 'dependency symmetry' proposed by Hoffman and Najjar (1986), whereby the minority group wants to get closer to the majority group in order to participate in their success. The minority meeting with the majority group is in the context of learning tasks (Davidovich et al., 2006, 2009; Rinawi, 2003). We can learn from this that student behavior is affected by the Israeli-Arab conflict. The students' attitude is task oriented; they want to take advantage of the situation. This was a stronger tendency among Arab students who benefit more from learning interaction with Jews, improve their Hebrew language, and their academic achievements are better. Arab students are more open to learning through social interaction because they want the Jewish students help them improve their grades (Council of Higher Education, 2013; Lufi \& Parish-Plass, 2010).

Table 1 also demonstrates that social interaction is related only to study matters; both minority and majority groups are more reluctant to interact regarding activities that are more socially and less study-oriented. We can say here, that students who come to the Galilee colleges are more concerned with studying than social interaction - they probably have other friends from the past (army, elementary, and high school) and prefer to socialize with them. This can also be explained by the low status of the majority of the students in Galilee peripheral colleges. The students wish to finish their bachelor's degree and find work to improve their living standard. They are not interested in wasting their time and money on social interaction just for fun without a meaningful, materialistic purpose.

In conclusion, this study shows that social contacts were formed mainly on the basis of functional self-serving and showed a slow change of perception of the other's personality traits. The Galilee colleges provide an opportunity for cultural encounters with different groups, although this is not always out of choice. A significant percentage of the students are from relatively poor socioeconomic backgrounds and study at these colleges because they are accessible and charge lower fees - their choice is based on economic and academic constraints. Some of the students register at Galilee colleges because their low grades preclude their acceptance by other educational institutions and so they are accepted into these colleges by default. Once at college, they cannot avoid the encounter between groups, whereas Israeli society outside the colleges is generally characterized by separation of Jews and Arabs.

This research can shed light on secondary transfer effect (Pettigrew, 2009; Pettigrew \& Troop, 2011), since the first contact occurred in the classroom, but secondary interactions were outside the lectures. Although most of the social contacts were surrounding study issues, they took place outside the classroom. The students wanted to broaden their experience and complex contact opportunities occurred mostly on campus; this was true for both out and in-group activities (although this tendency is stronger in the in-group compared to the out-groups contacts). Complex contacts off campus fell in both in and out-groups.

The findings for the change in attribution of stereotypes show that the change was small for all groups. In contrast, the Arabs in Israel saw the Jews more negatively regarding every characteristic. This may be because college studies are frustrating for them, since Jews have better academic achievements (Council for Higher Education, 2013; Lufi \& Parish-Plass, 2010). Their low scholastic achievements might make them attribute negative qualities to their Jewish counterparts.

The innovation in this study has been from a theoretical point of view, emphasizing the interaction between length of exposure to the other, openness to social contacts with other groups, and the change of attitude regarding personality traits. Length of exposure was found to be a decisive influence for social gathering, where the differences between the first and third year were significant. Thus far, the time factor has not been tested by other researchers. This study emphasizes the importance of forming social structures that will channel social contact for the purposes of improving social attitudes. The study found that there is a desire for social interaction, and the groups are open to social contact, but the ongoing Jewish-Arab conflict in the background probably hinders significant change in attitudes to personality traits.

Another point emphasized in this research is examining intergroup relations in natural conditions without designing an artificial study as in other cases (Allport, 1954; Amir, 1976; Binder et al., 2008; Cook, 1978; Eshel et al., 2007; Golan \& Shalhoub-Kevorkian, 2014; Hewstone \& Brown, 1986; Pettigrew, 2009; Pettigrew \& Troop, 2000, 2006, 2011; Sidanius et al., 2008; van Laar et al., 2005). The question which now arises is: can we relate on natural ground, that both groups will overcome mistrust and prejudice, to achieve a more positive mood and acceptance as was found in other research? (Binder et al., 2009; Pettigrew and Troop, 2006: 766; Troop et al., 2006).

The study results can indicate only the beginning of a positive contact process, the contact interaction with the outgroup was growing, while interactions over the years in the 
in-group were falling. These findings are encouraging, since the students in multicultural colleges learned that student from the out-group can be of assistance in issues connected with studying. But Table 2 shows that there are still issues of mistrust and negative prejudice between the groups. Although they have some experience in social interactions, they are not willing to change their attitude toward personality traits of the out-group.

The change in attitude was small, only in a behavioral dimension, but not in a cognitive one: the prejudice regarding personality traits remain unchanged. We can conclude that in a natural situation without intentional interference the results indicate only partial change (on a functional basis). The natural situation is insufficient; for better results we need to consider more thorough measures. It is possible, that to also create cognitive change toward traits stereotyped in the out-

\section{References}

Agmon, S., Schneider, S., \& Sagy S. (2005). The development of group defense mechanisms and group identity changes in Israeli Jewish and Arab students: The early stages (Part 1). Mikbatz: Israel Journal of Group Psychotherapy, 10, 54-75. [Hebrew]

al-Haj, M. (1994). Jewish-Arab encounter at the University of Haifa. Haifa: Haifa University Press.

Allport, G.W. (1954). The nature of prejudice. Reading, MA: Addison-Wesley.

Amir, Y. (1976). The role of intergroup contact in change of prejudice and ethnic relations. In P.A. Katz (Ed.), Towards the elimination of racism (pp. 245-308). New York: Pergamon Press.

Arad, N. (2007). The literacy experience of Arab students at Bar-Ilan University. (Unpublished master's thesis). BarIlan University, Ramat Gan, Israel. [Hebrew]

Aronson, E., Blaney, N., Stephin, C., Sikes, J., \& Snapp, M. (1978). The jigsaw classroom. Beverley Hills, CA: Sage Publishing Company.

Baumgartner, M. P. (1988). The moral order of a suburb. New York: Oxford University Press.

Binder, J., Zagefka, H., Brown, R., Funke, F., Kessler, T., Mummendey, A,... Levens, J. P. (2009). Does contact reduce prejudice or does prejudice reduce contact? A longitudinal test of the contact hypothesis among majority and minority groups in three European countries. Journal of Personality and Social Psychology, 96, 843-856.

Boulding, K. E. (1957). Organization and conflict. Journal of Conflict Resolution, 1(2), 122-134.

Boulding, K. E. (1963). Conflict and defense: A general theory. New York: Harper Bros.

Cook, S.W. (1978). Interpersonal and attitudinal outcomes in cooperating interracial groups. Journal of Research and Development in Education, 12, 97-113.

Council for Higher Education. (2013). Pluralism and equal opportunity in higher education: Expanding access for Arabs, Druze and Circassians in Israel. Jerusalem: CHE, Planning \& Budgeting Committee. [Hebrew]

Davidovitch, N. \& Iram, Y. (2005). Higher education at a crossroads: The contribution of the regional colleges to higher education in Israel. In The end of the academe in Israel? (pp.312-359). Studies in Education. Haifa: Haifa University, Department of Education. [Hebrew] group, we need to create intentional study, or use the jigsaw technique. Further research would help resolve the questions raised here.

We can learn from the jigsaw experience that it is a useful tool to try and use in the Israeli colleges in the Galilee. Although the classes are heterogeneous and the atmosphere encourages tolerance between Jews and Arabs, the classes are very big and teaching techniques do not employ the jigsaw system. We think it would be very beneficial to embrace this technique; maybe with close relationships in a small classroom the students can overcome their fear and change their attitude to be more positive in the cognitive dimension too (Aronson et al., 1978). It will be interesting in future research to test the jigsaw system in Israeli colleges, and examine it effects on this matter.

Davidovitch, N., Soen, D., \& Kolan, M. (2009). The place of the academic campus in the relationship between conflicted populations: The case of Israel. Judea and Samaria Research Studies, 18, 391-402. [Hebrew]

Davidovitch, N., Soen, D. \& Kolan, M. (2006). Student profiles and reciprocity between Arab and Jewish students on academic campuses. Judea and Samaria Research Studies, 13, 100-113. [Hebrew]

Dovidio, J. F., Gaertner, S. L., \& Kafati, G. (2000). Group identity and intergroup relations: The common in-group identity model. In Thye, S. R., Lawler, E. J., Macy, M. W., \& Walker, H. A. (Eds.), Advances in group processes, 17, 1-35. Stanford: CT: JAI Press.

Dovidio, J. F., Gaertner, S. L., \& Kafati, G. (2003). Intergroup contact: Theory, research and new perspectives. Annual Review of Psychology, 49, 65-85.

Eshel, Y., Kurman, J., Zehavi, N., \& Sbeit, K. (2007). Determinants of absorption courses for minorities in a university setting: Acculturation strategies and attitudes of the majority as perceived by Arab and Ethiopian students. Megamot, 45(1), 53-74. [Hebrew]

Golan, D. \& Shalhoub-Kevorkian, N. (in press). Communityengaged courses in a conflict zone: A case study of the Israeli academic corpus. Journal of peace education.

Hewstone, M. (1986). Contact and conflict in intergroup encounters. R. Brown (Ed.). New York: Basil Blackwell.

Hoffman, Y., \& Najjar, K. (1986). Willingness to normalize social relations between Jewish and Arab high school students. Iyunim B 'hinukh, 43-44, 103-118. [Hebrew].

Hornsey, M. J., \& Hogg, M. A. (2000). Subgroup relations: A comparison of mutual intergroup differentiation and common ingroup identity models of prejudice reduction. Personality and Social Psychology Bulletin, 26, 242-256.

Kimmerling, B. (1998). New Israelis - A plurality of cultures without multiculturalism. Alpayim 16, 264-308. [Hebrew]

Lawler, J. E. (Ed.) (1985). Advances in group processes: Vol. 2. Greenwich, CT: JAI Press.

LeVine, R. A., \& Campbell, D. T. (1972). Ethnocentrism: Theories of conflict, ethnic attitudes, and group behavior. New York: John Wiley.

Litvak-Hirsh, T. and Bar On, D. (2008). Meeting in time perspective: the contribute of a mutual workshop on identity design in young Jews and Arabs in Israel. Mipgash (27): 57-80. [Hebrew] 
Lufi, D., \& Parish-Plass, J. (2010). Differences between Arab and Jewish students in demographic and personality variables and their connection to academic success. Iyunim B'hinukh, 1-2, 259-273. [Hebrew]

Nahum, A. (2006). Minority inside the Majority: the identity Colleges, work of Arab students that learns in Israeli

for Master degree. Ramat Gan: Bar Ilan university. [Hebrew]

Pettigrew, T. F. (1971). Racially separate or together? New York: McGraw-Hill.

Pettigrew, T. F. (2009). Secondary transfer effect of contact: Do intergroup contact effects spread to noncontacted outgroups? Social Psychology, 40, 55-65.

Pettigrew, T. F., \& Troop, L. R. (2000). Does intergroup contact reduce prejudice? Recent meta-analytic findings. In S. Oskamp (Ed.), Reducing prejudice and discrimination: The Claremont Symposium on applied social psychology (pp. 93-114). Mahwah, NJ: Erlbaum.

Pettigrew, T. F., \& Troop, L. R. (2006). A meta-analytic test of intergroup contact theory. Journal of Personality and Social Psychology, 90, 751-783.

Pettigrew, T. F., \& Troop, L. R. (2011). When groups meet: The dynamics of intergroup contact. New York: Psychology Press.

Rabinowitz, D. \& Khawla, A. (2002). The stand-tall generation. Jerusalem: Keter Publications. [Hebrew]

Rinawi, K. (2003). Arab society in Israel: An ambivalent agenda. Tel Aviv: The College of Management. [Hebrew]

Samahar, Z., (1999). A comparison of self-disclosure in counseled groups of adolescent Jewish and Arab youth. (Unpublished master's thesis). University of Haifa, Haifa. [Hebrew]

Samucha, S. (2001). Jewish-Arab relations in Israel as a Jewish and democratic country. In Yuchtman-Ya'ar, E., \& Shavit, Z. (Eds.), Trends in Israeli society (pp. 231-365). Tel Aviv: The Open University of Israel. [Hebrew]

Schmadar, T., Major, B., \& Gramzow, R. H. (2001). Coping with ethnic stereotypes in the academic domain: Perceived injustice and psychological disengagement. Journal of Social Issues, 57(1), 93-111.

Schwarzwald, J., \& Tur-Kaspa, M. (1997). Perceived threat and social dominance as determinants of prejudice toward Russians and Ethiopians. Megamot, 38, 504-527. [Hebrew]

Sheriff, M. (1966). Group conflict and co-operation: Their social psychology. London: Rutledge \& Kegan Paul.

Sindanius, J., Levin, S., van Laar. C., \& Sears. D.O. (2010). The diversity challenge: Social identity and intergroup relations on the college campus. New York: The Russell Sage Foundation.

Soen, D. (1999). Unpublished position paper. Academic College of Judea and Samaria. [Hebrew]

Tajfel, H. \& Turner, J.C. (1994). The social identity theory of inter group behavior, in

Taylor, D. M. and F. M. Moghadam (eds). Theories of inter group relations:

International social psychological perspectives (56-

80). Westport: Prager.

Troop, L. R. (2006). Stigma and intergroup contact among members of minority and majority status groups. In S. Levin, \& C. Van Laar (Eds.), Stigma and group inequality: Social psychological perspectives (pp. 171-191). Mahwah, NJ: Lawrence Erlbaum. van Laar, C., Levin, S., Sinclair, S., \& Sidanius, J. (2005). The effect of college roommate contact on ethnic attitudes and behavior. Journal of Experimental Social Psychology, 41, 329-345.

Van Laar, C., Sidanius, J., \& Levin, S. (2008). Ethnic related curricula and intergroup attitudes in college: Movement towards and away from the ingroup Journal of Applied Social Psychology, 38 (6), 1601-1638.

Williams, R. M. (1947). The reduction of intergroup tensions. New York: Social Science Research Council. 